\title{
Ueber Parthenogenesis
}

von

H. S $c h a u m$.

$I_{n}$

der October bis December-Nummer des Jahrgangs 1862 der Stettiner entomologischen Zeitung ist eine Rede über Parthenogenesis abgedruckt, die Prof. v. Siebold einige Monate vorher in einer öffentlichen Sitzung der Münchner Academie gehalten hatte. In derselben hat der Verf. aufs Neue die Erscheinungen besprochen, welche ihn bestimmt baben, die Parthenogenesis mancher Insecten, namentlich einiger Sackträger und der Honigbiene, als eine auf viele genaue und oft wiederholte Untersuchungen gestützte Thatsache der Wissenschaft zu übergeben.

Trotz der Autorität v. Siebold's ist diese Lehre von den meisten Zoologen mit stillem Mifstrauen aufgenommen worden, das sich noch bedeutend gesteigert hat, seit die auf dem Gebiete der Botanik versuchte Anwendung der Lehre als eine Uebereilung erkannt worden ist. Die Beobachtungen, dafs aus wahren Eiern gewisser Sackträger auch ohne Begattung Raupen auskriechen und dafs die Drohnen sich nur aus Eiern der Bienenkönigin und einzelner Arbeitsbienen entwickeln, auf die ein vom Männchen gelieferter Same nicht eingewirkt hat, sind nun allerdings bei der Sorgfalt, mit der sie angestellt sind, nicht in Zweifel zu ziehen, aber rechtfertigen diese Beobachtungen auch wirklich den Schlufs, dafs hier eine parthenogenetische Entwicklung stattfinde? Ehe eine Erscheinung als Thatsache anerkannt werden kann, die ein, wie es schien, fundamentales Geselz des organischen Lebens umstöfst, und der gegenüber daher das Widerstreben der Physiologen ein völlig berechtigtes ist, mufs jede Möglichkeit einer andern Erklärung der Thatsachen ausgeschlossen werden. Es existirt hier aber in der That eine andere Erklärung, auf die mich Dr. Pringsheim in mündlichem Gespräche wiederholt und schon vor längerer Zeit hingewiesen hat, und die einen Schlüssel zu allen den wunderbaren, von Siebold zur Sprache gebrachten Vorgängen im Leben der Bienen liefern würde, die nämlich, dafs die Bienenkönigin und die eierlegenden Arbeitsbienen sowie jene Sackträger Hermaphroditen sind, neben den weiblichen auch männliche bisher nur übersehene Generationsorgane besitzen und selbst den Samen liefern, der zur Befruchlung der Eier erforderlich ist. 
Allerdings sind unter den Insecten Hermaphroditen bisher nur als vereinzelte Abnormitäten, bei denen die eine Hälfte des Thieres männlich, die andere weiblich war, beobachtet worden; aber schon das Vorkommen solcher Abnormitäten spricht für die Möglichkeit eines in gewissen Fällen normalen Hermaphroditismus, der wenigstens für eine Familie der Arthropoden, die Cirripidien, längst festgestellt ist.

Auch die Thatsache, dafs neben solchen Hermaphroditen, wie die Bienenkönigin und die flügellosen Sackträger sein würden, wirkliche Männchen (Drohnen und geflügelte Schmetterlinge) erscheinen und eine Begattung vollziehen, würde nicht mehr jeder Analogie entbehren, seit wir durch Darwin die complementären, nur zeitweise erscheinenden Männchen der Cirripedien kennen gelernt haben. Die Bestätigung dieser Vermuthung würde zugleich wenigstens für einige Fälle den béstimmten Beweis liefern, dafs verschiedene Samenelemente für jedes der beiden Geschlechter existiren.

Ehe die hier versuchte Erklärung der Thatsachen beseitigt ist, die zwar mit den bisherigen Erfahrungen über die Generationsorgane der Insecten, aber nicht mit dem allgemeinen, durch andere Beobachtungen immer mehr bestätigten Gesetze der Zeugung in Widerspruch tritt, kann die Lehre der Parthenogenesis kaum für eine genügend begründete gelten.

$\mathrm{Zu}$ erneuten Untersuchungen der Geschlechtsorgane der in Betracht kommenden Insecten, zu denen auch die Gallwespen gehören, diejenigen Zoologen und Physiologen anzuregen, die in der glücklichen Lage sind, sich das genügende Untersuchungsmaterial verschaffen zu können '), ist die Hauptaufgabe der gegenwärtigen Mittheilung. Ich kann es hierbei nicht unterlassen, besonders auf den schlauchförmigen Anhang aufmerksam zu machen, der neben der Giftdrüse in die Scheide der Bienenkönigin einmündet und dessen Entwicklung in den Leuckart'schen Abbildungen (Berlepsch, die Biene. Mühlhausen 1860 p. 19 ff. fig. 3. 4. 5.) mit der Ausbildung der Ovarien in Verhältnifs zu stehen scheint. Dafs der flüssige lnInhalt dieses Schlauches, wie v. Siebold annahm, dazu diene, einen klebrigen Eierüberzug zu liefern, ist a. a. 0 . bereits bestritten.

') Die grofse Schwierigkeit, das nöthige Material (Bienenköniginnen eierlegender Arbeiter, die nur ganz einzeln erschienen, und Sackträger, die ein lokales Vorkommen haben) in genügender Menge zu erhalten, ist wohl hauptsächlich die Veranlassung gewesen, dafs die Siebold'schen Untersuchungen bisher nicht öfter wiederholt und weiter verfolgt wurden. 


\section{$2 \mathrm{BHL}$ Biodiversity Heritage Library}

Schaum, Herm. Rud. 1863. "Ueber Parthenogenesis." Berliner entomologische Zeitschrift / herausgegeben von dem Entomologischen Vereine in Berlin 7(102), 93-94. https://doi.org/10.1002/mmnd.18630070108.

View This Item Online: https://www.biodiversitylibrary.org/item/36389

DOI: https://doi.org/10.1002/mmnd.18630070108

Permalink: https://www.biodiversitylibrary.org/partpdf/209966

\section{Holding Institution}

Smithsonian Libraries

\section{Sponsored by}

Smithsonian

\section{Copyright \& Reuse}

Copyright Status: Public domain. The BHL considers that this work is no longer under copyright protection.

This document was created from content at the Biodiversity Heritage Library, the world's largest open access digital library for biodiversity literature and archives. Visit BHL at https://www.biodiversitylibrary.org. 